\title{
Sob o signo da degeneração: os "loucos-tísicos"
}

\section{Under the sign of degeneration: the "fools-thysics"}

\section{Claudio Bertolli Filho*}

Resumo: Este artigo tem como objetivo focar primeiramente a trajetória de vida e a morte de um homem negro, criminoso e acometido pela doença mental e pela tuberculose para, em seguida, discutir o encaminhamento oficial que era imposto a esse tipo de infrator no contexto da cidade de São Paulo nas primeiras décadas do século XX. Para tanto, recorreu-se às fontes documentais produzidas pelas ciências médicas sobre os personagens classificados por ela como sendo "tipos degenerados".

Palavras-chave: Degenerescência; afro-brasileiros; psiquiatria brasileira.

Abstract: This article aims to focus primarily on the life trajectory and death of a black man, criminal and affected by mental illness and tuberculosis, and then discuss the official referral that was imposed on this type of offender in the context of the city of São Paulo, in the first decades of the twentieth century. It was used the documentary sources produced by the medical sciences on the characters classified by her as being "degenerate types".

Keywords: Degeneration; Afro-Brazilians; Brazilian psychiatry.

* Doutor em História pela Universidade de São Paulo (USP). Professor livre-docente aposentado na UNESP, atuante junto ao Programa de Pós-graduação em Comunicação da UNESP - campus de Bauru. ORCID: https://orcid.org/0000-0003-3584-9736. E-mail: cbertolli@uol.com.br. 
m meados da década de 1920, a cidade de São Paulo contava com aproximadamente 550 mil habitantes, os quais protagonizavam a acelerada metamorfose do cenário paulistano, que então testemunhava os momentos derradeiros da substituição da imagem de antigo "burgo dos estudantes" pela representação da "metrópole do café". ${ }^{1}$ Emblemando o processo modernizador, fluía uma força de trabalho composta por representantes de múltiplas nacionalidades cujo engajamento no mundo do trabalho alimentava o dinamismo do novo cenário urbano-industrial. Com raras exceções, esses operários constituem-se nos personagens privilegiados por uma rica produção historiográfica que, mesmo não abrindo mão da perspectiva crítica, persiste no enfoque dos trabalhadores suficientemente enquadrados no ambiente da produção segundo os requisitos próprios do capitalismo.

No entanto, à sombra da "Chicago brasileira" ou "Manchester sul-americana" - como reiteravam com indisfarçado orgulho as vozes que invocavam a cidade no início do século passado -, sobrevivia uma extensa comunidade de excluídos que, até o momento, ainda não foram suficientemente contabilizados e nem receberam a merecida atenção dos estudiosos. Esse agrupamento era composto de interioranos paulistas, migrantes vindos de outros estados, um número relativamente pequeno de estrangeiros e, sobretudo, por africanos e seus descendentes, colocados em liberdade em 1888. Em 1925 um cronista retratou essa parcela de trabalhadores pobres de São Paulo como sendo uma "choldra" cujos integrantes "passam quinze dias do mês reclusos na Cadeia Pública e que nos outros quinze dias, em liberdade, dormem no Albergue". ${ }^{2}$

Esse contingente marginalizado atuava nas franjas dos processos de trabalho, contando com estreitas opções de sobrevivência. Enquanto que as mulheres eram recrutadas para os serviços domésticos, enveredavam para a prostituição ou tornavam-se pedintes, os homens executavam tarefas sazonais de baixíssima renumeração nas fazendas e chácaras que compunham o cinturão verde do município. Além disso, muitos se aglomeravam nas proximidades do mercado municipal próximo da área central da cidade, conseguindo o seu sustento na informalidade combinado com atividades ilegais ou próximas disso. Nessa condição, muitos deles eram punidos pelos agentes da polícia cuja ação encontrava apoio no Código Penal aprovado em 1890, cujo artigo 399 estipulava a pena de prisão por 15 a 30 dias para os maiores de 14 anos de idade que não comprovassem exercer uma profissão ou ter um meio legal de subsistência, e que não apresentassem provas de terem endereço fixo de domicílio. Para os legisladores, parecia claro que, nessas condições, o indivíduo provinha sua subsistência "por meio de ocupação proibida por lei, ou manifestadamente ofensiva da moral e dos bons costumes". ${ }^{3}$

1 BRUNO, Ernani Silva. História e tradições da cidade de São Paulo. Rio de Janeiro: José Olympio, 1953. 3 v.

2 FLOREAL, Sylvio. Ronda da meia-noite. São Paulo: Paz e Terra, 2003. p. 50.

3 BRASIL. Decreto $\mathbf{n}^{\circ} \mathbf{8 4 7}$, de 11 de outubro de 1890. Promulga o Código Legal dos Estados Unidos do Brasil. Disponível em: https://www2.camara.leg.br/legin/fed/decret/1824-1899/decreto-847-11-outubro-1890-503086publicacaooriginal-1-pe.html. Acesso em: 11 maio 2020. 
O teor desta lei, reproduzida com ligeiras alterações nos dispositivos legais de muitos outros países, refletia as perspectivas legais e médicas adotadas pelas elites que haviam incorporado os ensinamentos das ciências europeias, as quais rotulavam as comunidades de trabalhadores pobres como agrupamentos compostos por homens e mulheres "degenerados" e fomentadores de múltiplas ameaças à ordem social e à saúde pública. Nesse sentido, ciência e ideologia burguesa entrelaçavam-se, ditando as estratégias de vigilância e punição impostas àqueles que eram tidos como seres indesejáveis porque descompromissados com o trabalho e com os padrões orientadores do cotidiano e da moral moderna. ${ }^{4}$

Frente a esse contexto, o objetivo desse artigo é explorar as análises e procedimentos médicos centrados em um "tipo degenerado" cuja presença mostrava-se corriqueira na "Metrópole do café" e nas demais cidades brasileiras: o homem negro, desprovido de emprego e de residência fixa. Estreitando o foco, a opção recaiu inicialmente em uma série de eventos que, em 1927, foi espetacularizada pela imprensa sob o título de "o caso do preto Amaral", despertando a curiosidade pública e chamando a atenção da comunidade médica. Relegado ao semiesquecimento por um longo período, o afro-brasileiro José Augusto do Amaral, o "preto Amaral" teve seu processo criminal preservado no Museu da Polícia de São Paulo, circunstância que permitiu que o personagem e os crimes a ele imputados voltassem aos holofotes nas últimas décadas. Nessa situação, Amaral tornou-se tema de pesquisa acadêmica, ${ }^{5}$ de inúmeros textos publicados em jornais e revistas populares, e de dois livros de pendor sensacionalista que exploram os "grandes crimes" ocorridos no pretérito paulistano, sendo neles erroneamente apresentado como o primeiro assassino em série brasileiro. ${ }^{6}$ Além disso, Amaral foi lembrado em uma encenação teatral comprometida com a denúncia do racismo baseado nos postulados eugenistas. ${ }^{7}$

Detido, Amaral faleceu na prisão antes de ser levado a julgamento pelos crimes que fora acusado, impedindo que o destino do prisioneiro seguisse os protocolos impostos aos infratores destituídos de bens e considerados "degenerados irrecuperáveis". Por isso, essa pesquisa tem continuidade com o enfoque do encaminhamento médico-legal dado a outros indivíduos anônimos que cometeram delitos semelhantes àqueles que levaram Amaral à prisão. Para tanto, utilizou-se sobretudo as fontes documentais produzidas pela corporação hipocrática, as quais primam pela apresentação minuciosa dos acontecimentos e dos personagens envolvidos nas tramas tomadas como objetos de suas investigações.

4 PESET, José Luís. Ciencia y marginación. Barcelona: Critica, 1983.

5 CAMPOS, Paulo Fernando de Souza. Os crimes do preto Amaral: representações da degenerescência em São Paulo - 1920. 2003. Tese (Doutorado em História) - Faculdade de Ciências e Letras, Universidade Estadual Paulista, Assis, 2003.

6 FONSECA, Guido. Crimes, criminosos e a criminalidade em São Paulo (1870-1950). São Paulo: Resenha Tributária, 1988; CASOY, Ilana. Serial killers made in Brasil. Rio de Janeiro: Ediouro, 2009.

7 COELHO, Sérgio Salvia. Montagem expõe o racismo implícito do povo brasileiro. Folha de S. Paulo, São Paulo, 17 mar. 2007. Disponível em: https://www1.folha.uol.com.br/fsp/acontece/ac1703200703.htm. Acesso em 12 maio 2020. 
Desde que foi posto atrás das grades, Amaral foi apresentado pelos jornalistas e avaliado pelos médicos como um típico exemplar de indivíduo degenerado. Isso faz que, antes de discorrer sobre os macabros acontecimentos que teve o criminoso como personagem central, seja necessário abordar o significado que os estudiosos do início do século passado atribuíam ao termo "degenerado" e suas implicações na trajetória de vida de quem fora assim rotulado.

\section{A teoria da degenerescência}

A IDEIA DE DEGENERESCÊNCIA dos seres vivos foi instituída pelo Conde de Buffon (1707-1788) ao buscar explicar as características físicas e culturais dos africanos, tomando como padrão ideal o homem europeu. Em 1857 o médico francês Bénédict Auguste Morel retomou o termo, informando que, em um tempo primordial, os seres humanos, como fruto da criação divina, comportavam qualidades que foram sendo paulatinamente aperfeiçoadas. Entretanto, devido a processos biológicos específicos de cada "raça", combinados com as condições impostas pelo meio ambiente físico e cultural e ainda, devido às imperfeições das instituições sociais, alguns grupos humanos estavam regredindo à condição animal, tornando-se assim inconvenientes para a existência coletiva.

Seguindo essa linha explicativa, Morel definiu a degenerescência como o "desvio do tipo primitivo ou normal de humanidade" e o degenerado como uma "variedade doentia de homem", um personagem que, aviltado pela "degeneração progressiva", estava fadado a ser improdutivo e perigoso para a comunidade, constituindo-se em "uma monstruosidade de ordem intelectual e moral". Por isso, o escritor convocou sobretudo os médicos e os advogados de todas as nações para encabeçarem uma cruzada contra as estirpes degradadas, alertando que se nada fosse feito de imediato, o porvir da humanidade poderia estar sendo colocado em risco. ${ }^{8}$

As especulações morelianas dominaram as discussões médicas e políticas da segunda metade do século XIX e das primeiras décadas do século seguinte, sendo adotadas inclusive por Cesare Lombroso (1836-1900), que incluiu os delinquentes em geral e os trabalhadores anarquistas no rol dos degenerados. No Brasil um dos primeiros seguidores das propostas de Morel e de Lombroso foi o médico Raimundo Nina Rodrigues (1862-1906), que entrelaçou a noção de degenerescência com o ideário evolucionista de Armand Corre (1841-1908). Este último autor analisou o perfil dos criminosos negros das colônias francesas situadas no continente americano e Nina Rodrigues estendeu suas conclusões para as comunidades afro-brasileiras. Em um livro publicado em 1894, o médico brasileiro teceu várias referências aos estudos de Armand Corre, reproduzindo longos trechos da obra do francês. Uma dessas citações é a seguinte:

O negro não tem mau-caráter, mas somente caráter instável como a criança, e como a criança - mas com esta diferença que ele já atingiu a maturidade

8 MOREL, Bénédict Auguste. Traité des dégénérescences physiques, intellectuelles et morales de l'espèce humaine, et des causes qui produisent ces variétés maladives. Paris: J.B. Baillière, 1857. p. 683. 
de seu desenvolvimento fisiológico, a sua instabilidade é a consequência de uma cerebração incompleta. (...) O negro crioulo conservou vivaz os instintos brutais do africano; é rixoso, violento nas suas impulsões sexuais, muito dado à embriaguez e esse fundo de caráter imprime o seu cunho na criminalidade colonial atual. ${ }^{9}$

No início do século XX, essas ideias foram atualizadas por Jules Héricourt (1850-1938), um reputado docente da Faculdade de Medicina de Paris. Em seu livro mais conhecido, ele se empenhou em articular o conceito de degenerescência com os postulados da eugenia, identificando a tuberculose, o alcoolismo e a sífilis, que tinham como corolário alterações do estado mental e a esterilidade, como marcas denunciadoras da condição degenerada. Repetindo quase as mesmas palavras de Morel, ele advertiu que, se nada fosse feito para conter a expansão numérica dos degenerados, as nações padeceriam de despovoamento e, em caso extremo, a Humanidade poderia ser extinta. ${ }^{10}$

Os ensinamentos de Héricourt foram prontamente assimilados pela elite intelectual brasileira, a qual reprisando o que acontecia na Europa e nos Estados Unidos, buscou juntar forças para fazer aprovar uma lei que impedisse a formação de casais que, pelo menos um dos membros, fosse avaliado como degenerado. Como essa iniciativa não alcançou sucesso, restou aos "defensores da sociedade" reforçar os dispositivos de vigilância e punição sobre os infratores.

Foi nesse ambiente que, dentre tantas tragédias e personagens anônimos, ganhou visibilidade pública o delituoso Amaral, um homem que se encaixava perfeitamente no perfil de "monstro" preconizado pelo professor Morel e seus discípulos.

\section{O "caso do preto Amaral"}

EM JANEIRO DE 1927, pouco após José Augusto do Amaral ser detido pela polícia sob a acusação de ter praticado uma série de assassinatos seguidos do estupro dos cadáveres, o psiquiatra Antônio Carlos Pacheco e Silva, que então ocupava o cargo de diretor do Hospício de Juqueri, e José Rebello Silva, clínico da polícia, foram convocados para avaliarem o estado físico e mental do prisioneiro. A série de encontros que os especialistas mantiveram com o prisioneiro resultou não só em um laudo circunstanciado sobre o paciente, mas também em um artigo científico publicado e assinado pelos dois médicos. ${ }^{11}$ Em 1940, quando Pacheco e Silva já se firmara como o principal psiquiatra do país e ocupava o posto de professor catedrático de Clínica Psiquiátrica da Faculdade de Medicina da Universidade de São Paulo (USP), lançou uma de suas obras mais reputadas, na qual retomou e comentou o interrogatório policial e o laudo que ele e Rebello Silva teceram

9 NINARODRIGUES, Raimundo. As raças humanas e a responsabilidade penal no Brasil. Salvador: Livraria Progresso, 1957. p. 115.

10 HÉRICOURT, Jules. Les maladies des sociétés: tuberculose, syphilis, alcoolisme et stérilité. Paris: Ernest Flammarion. 1920. p. 211

11 PACHECO E SILVA, Antônio Carlos; SILVA, José Rebello. Um sádico-necrophilo. O preto Amaral. Archivos da Sociedade de Medicina Legal e Criminologia, São Paulo, v. 2, n. 2, p. 91-112, 1928. 
em 1927, apresentando Amaral como um caso exemplar de degenerado sadonecrófilo. ${ }^{12}$

Segundo as informações constantes nesse livro, reproduzidas tanto do interrogatório policial quanto do laudo médico, no anoitecer do primeiro dia do ano de 1927, um sábado, um indivíduo que transitava no trecho do km 39 da estrada velha de São Miguel, próximo à Vila Esperança, na zona leste paulistana, deparou-se com uma cena sinistra: adentrando poucos metros em um atalho da estrada, jazia o corpo sem vida de um adolescente de cor branca e olhos verdes, trajando apenas uma camisa em farrapos, e com visíveis sinais de violência sexual. O cadáver encontrava-se em decúbito lateral esquerdo e apresentava evidências de morte violenta, inclusive porque em seu pescoço estava fortemente atado um cinto de brim branco, de $85 \mathrm{~cm}$ de comprimento. O fato foi imediatamente levado ao conhecimento das autoridades e, na manhã seguinte, o corpo foi reconhecido por um carroceiro, irmão da vítima. O cadáver foi identificado como sendo de A.L., de 15 anos de idade, um operário de uma fábrica de tecidos, que na madrugada do ano-novo partira de sua residência com destino ao trabalho e que não mais regressara para casa.

Poucos dias depois, compareceu ao Gabinete de Investigações um trabalhador não identificado que desejava prestar algumas declarações. O informante disse que, tendo lido nos jornais notícias sobre o horripilante crime, reunia motivos para suspeitar de um sujeito negro que vira no dia do crime em companhia de dois menores, sendo que um deles correspondia à descrição divulgada de A.L.. Acrescentou ainda que o suspeito almoçara com um dos rapazes no botequim Meio-Dia, situado nas vizinhanças do Mercado Central, onde consumiu uma garrafa de vinho, pagou seu almoço e o do jovem acompanhante e presenteou a vítima com "uma prata de $2 \$ 000 "$. Ao encerrar suas declarações, o depoente disse ainda que o "aludido preto" era pessoa conhecida na região do mercado municipal, tratando-se de um vagabundo que vivia da exploração do jogo de cartas.

Às 16 horas do dia 5 de janeiro, um agente policial conseguiu localizar o suspeito que, levado à Chefatura de Investigações e Capturas, declarou às autoridades chamar-se José Augusto do Amaral, solteiro, 56 anos de idade, natural da cidade mineira de Conquista, tendo assentado praça no Exército e posteriormente na Força Pública de São Paulo e que, após desertar de ambas as instituições, decaíra para a vadiagem, a bebida e a jogatina, tendo sido por estes motivos preso em diversos momentos da sua atribulada existência, indicando como locais de detenção as cidades de São Paulo, Bauru e Santos. Interpelado, Amaral confessou ser o autor do assassinato na estrada de São Miguel, confirmando que havia almoçado com o rapaz e, "com grande cinismo e relativa indiferença", acrescentou que, finda a refeição, convidou o quase-menino a tomarem o bonde para o bairro da Penha. Apeando no ponto final da linha, Amaral e o jovem passaram a caminhar pela estrada de São Miguel, onde o criminoso visitou diversos botequins e ingeriu inúmeras doses de aguardente. Em seguida, ambos continuaram a jornada, que teve o trágico 
desfecho, assim retratado pelo assassino, com palavras mediadas por um escrivão da polícia:

Ao chegarem a um lugar escuro, de onde se desdobra uma sucessão de colinas, pouco mais ou menos no quilômetro 39, enveredou por um atalho da estrada recém-construída e aí, sem nada dar a perceber ao menor, nele se atracou num movimento brusco e, enlaçando-o fortemente com o braço esquerdo, esganou-o com a mão direita.

O menor sem nenhuma resistência, empalideceu e desmaiou. Ao abandonálo no chão, estava morto. Arrebatou-lhe então as calças, rasgou-lhe a camisa e satisfez sobre o cadáver seu apetite mórbido. ${ }^{13}$

Na sequência, Amaral passou a enumerar, espontaneamente, outros três crimes semelhantes que haviam sido por ele praticados em dezembro de 1926, nos distritos de Pinheiros, Santana e Brás, descrevendo cada um deles em detalhes e, de imediato, conduziu os investigadores até um local ermo localizado na zona norte da cidade, indicando com exatidão onde ocultara os cadáveres de duas das suas vítimas. Ainda na noite do seu primeiro depoimento, o assassino confesso foi entrevistado por vários representantes da imprensa que, explorando o desejo do detido discorrer sobre sua vida e seus delitos, reuniram informações suficientes para publicarem reportagens que invocaram o criminoso nas manchetes como "preto Amaral" e, no corpo das matérias como "monstro negro", "papão de crianças", "bandido" e "besta fera". Durante o encontro com os jornalistas, Amaral também confidenciou que, por ter sido preso e confessado seus crimes, a partir de então poderia "dormir melhor", porque até aquele momento se sentia perseguido pelos fantasmas de suas vítimas, acrescentando que esperava ser tratado com "todo o rigor da justiça" e que, para ele, "bastava de tanto banditismo". ${ }^{14}$

No dia seguinte aos depoimentos à polícia e aos representantes da imprensa, o jornal A Gazeta publicou uma extensa reportagem sobre Amaral, mostrando que o modo de agir do criminoso era semelhante para com todas as suas vítimas:

Vagabundo, sem profissão nem vontade para trabalhar, viveu, novembro e dezembro, de expedientes e pequenos furtos. Após relatar os mais insignificantes pormenores de sua vida, nesse espaço de tempo fez o bandido a confissão horripilante de seus crimes. Contou que uma manhã, passando pela avenida Tiradentes, encontrou, sentado num banco, um rapazola de 16 anos, trajando paletó preto, chapéu e botina na mesma cor e calça branca. Sentou-se ao lado do mocinho. Conversaram. O rapaz disseIhe que tinha fome e ele ofereceu-se para lhe pagar café, indo ao botequim de um tal Cunha, na esquina da rua João Teodoro. Daí se dirigiram para as proximidades do campo de Marte, onde se realizava um jogo de futebol. Apreciaram algum tempo os futebolistas, internando-se, depois, no campo, indo deitar-se num bambual próximo. Ali, agarrou o rapaz, que resistiu, travando luta. Com a mão direita o bandido, esganou-o, asfixiando e praticando, em seguida, [o] mais repugnante crime. ${ }^{15}$

13 Ibidem, p. 362.

14 Ibidem, p. 363.

15 A Gazeta, São Paulo, p. 5, 06 jan. 1927 Apud SOUZA CAMPOS, Paulo Fernando de. Os crimes do "monstro negro": representações da degenerescência em São Paulo. In: XXII SIMPÓSIO NACIONAL DE HISTÓRIA 
Dispondo dos dados constantes no interrogatório policial e nos fatos que o detido confidenciara à imprensa, os doutores Pacheco e Silva e Rebello iniciaram a perícia médica, obtendo novas e mais precisas informações que seriam utilizadas no estabelecimento do diagnóstico físico e psicológico do criminoso confesso de quatro assassinatos. Questionando Amaral, souberam que ele era filho de escravos - o pai fora trazido do Congo e a mãe de Moçambique -, e que perdera os progenitores ainda jovem, tendo uma irmã da qual ignorava o paradeiro. Dentre seus antecedentes patológicos, o preso informou ter tido uma série de enfermidades típicas da infância e, na idade adulta, blenorragia e adenite, além de ter se tornado alcoólatra.

Em suas declarações aos médicos, Amaral acrescentou ainda sua trajetória como trabalhador. Após deixar a roça na qual era empregado desde criança, em 1906 serviu como corneteiro na Brigada Policial de Porto Alegre, sendo então vitimado por um surto psicótico, com alucinações visuais e cenestésicas que o levaram a sentir que dedos possantes the apertavam a garganta, fazendo-o sair correndo e usar sua arma para disparar tiros a esmo. Devido a esse episódio, foi conduzido a um asilo para alienados, onde dois meses depois, voltou a si. Ao receber alta médica, foi desligado da força policial e, dois anos depois estava novamente trabalhando, desta vez para a Comissão de Limites entre o Brasil e a Bolívia e, quando se encontrava alojado em um acampamento estabelecido nos arredores de Corumbá, foi vitimado por nova crise psicótica, evento que ele próprio justificou como decorrência do consumo combinado de aguardente e de maconha.

Afastado também desse emprego, serviu como policial em várias localidades do interior do país, sempre desertando ou sendo expulso das corporações militares por atos indisciplinares. Os médicos souberam então que o paciente raramente mantinha relações sexuais, mesmo assim sempre com "mulheres fáceis", as quais invariavelmente buscavam evitá-lo como freguês devido ao "crescimento desmedido" dos seus órgãos genitais. A causa dessa anomalia anatômica foi esclarecida por Amaral e anotada pelo psiquiatra, constituindo-se em um dos elementos para que os médicos concluíssem sobre a degeneração mental do paciente. Essas foram as anotações constantes do laudo elaborado pelos peritos:

Quando adolescente, aconselhado por companheiros, marcou com dois traços numa bananeira, até que tamanho desejava que o pênis crescesse. Passado algum tempo, lembrou-se subitamente do que havia feito, correu até a bananeira onde havia gravado os traços, mas já era tarde - a bananeira crescera muito e a distância entre os dois traços. (...) Cheio de receios, abateu a planta a machadadas, mas com muitas apreensões foi aos poucos se apercebendo de que nada mais havia a fazer, pois que seus órgãos genitais cresciam sempre, até atingirem as proporções atuais. ${ }^{16}$

- A interface regional: redes institucionais na construção do Brasil, 2003, João Pessoa/PB, Anais [...]. João Pessoa: UFPB, 2003, p. 1-6. Disponível em: https://anpuh.org.br/uploads/anais-simposios/pdf/201901/1548177542_53b44835d5582c8bef8aef071849a9a1.pdf. Acesso em: 12 maio 2020. 
Dando continuidade ao exame, os clínicos descreveram Amaral como um "tipo fisionômico pouco comum nos de sua raça", pois apresentava nariz aquilino e ligeiramente adunco, fronte fugidia e "rosto glabro", desprovido de pelos. Foi anotado também que, levando "vida ociosa" na cidade de São Paulo, na primeira semana de dezembro de 1926, ele travou amizade com outro negro marginalizado, Roque, que o incitou a conquistar suas presas sexuais com palavras carinhosas e mimos baratos e que, a partir daí, "não teve mais nem sossego e nem tranquilidade". Dizendo que nunca praticara a pederastia até então, o criminoso passou a aproximar-se de rapazes e afirmou ter praticado o ato sexual somente após certificar-se que suas vítimas estavam mortas.

Outros exames físicos e psiquiátricos foram realizados no criminoso, os quais levaram os dois médicos constatarem que, além do distúrbio mental, o paciente padecia de tuberculose bilateral em estágio avançado. De posse desses dados, os dois especialistas, declaradamente apoiados nas orientações de Lombroso e de outros discípulos de Morel, concluíram que o criminoso era vitimado pela "atrofia moral" que, por sua vez, o transformara em um "sádico-necrófilo".

Com esse laudo, o criminoso foi enviado à Penitenciária do Carandiru e, sem nenhum tratamento médico para as suas lesões pulmonares, chegou a óbito no dia 2 de junho de 1927, antes de ser julgado pelos seus crimes.

\section{A psicologia do tuberculoso}

SEAMARALNÃOTIVESSESUCUMBIDOfrenteàdoença, mesmosendocriminosoconfesso, éprovável que seria protegido pela inimputabilidade legal conferida aos portadores de patologias mentais, recebendo como sentença o confinamento pelo resto de seus dias no Hospício de Juqueri, instituição que contava com um número significativo de afrodescendentes tocados pela miséria material. ${ }^{17}$ Essa suposição ganha consistência por dois motivos. O primeiro deles é a semelhança dos delitos perpetrados por Amaral e por Febrônio Índio do Brasil que, no mesmo período, foi preso no Rio de Janeiro sob a acusação de assassinato e sevícia de inúmeras crianças e adolescentes. Julgado em 1929 Febrônio foi enviado da prisão para o hospício, onde permaneceu até 1984 , ano de sua morte. ${ }^{18} \mathrm{O}$ segundo motivo é que, em 1940, após reapresentar aos seus leitores a trama orquestrada em torno do "preto Amaral", Pacheco e Silva chamou a atenção dos seus leitores para a semelhança de seus crimes com os de Febrônio, reiterando a condição degenerada de ambos os delituosos. Nesse curso, o psiquiatra acrescentou o seguinte comentário sobre o encaminhamento a ser imposto a todos os criminosos do mesmo tipo:

17 CUNHA, Maria Clementina Pereira. O espelho do mundo: Juquery, a história de um asilo. Rio de Janeiro: Paz e Terra, 1986. p. 113.

18 CASOY, op. cit., p. 58 
Há uma verdadeira atrofia do senso moral e a perversidade das ações, sem motivos exteriores, são provas que o indivíduo age em consequência de um desvio do instinto. Verificada a não imputabilidade do criminoso, o mesmo deverá sofrer reclusão perpétua num asilo de alienados, medida que nos parece mais acertada que a detenção penitenciária. A volta de semelhantes anômalos mentais ao seio da sociedade deverá ser obstada por todos os meios, porquanto eles não tardam em recomeçar a atividade criminosa. ${ }^{19}$

Além da insanidade, Amaral carregava no seu corpo outra enfermidade agravante, a tuberculose, enquadrando-se na categoria clínica dos tísicos-loucos. Desde o último quartel do século XIX, a medicina passou a cogitar a interdependência entre as patologias mentais e a tuberculose pulmonar, o que resultou no afloramento de uma área do saber denominada "psicologia do tuberculoso". Nesse campo, a maior parte dos estudiosos postulava que a ação das toxinas produzidas pelo "germe da tísica" ou, ainda, a ação da febre tuberculosa sobre o sistema nervoso, causavam perturbações no cérebro que, nas situações mais agudas, levavam ao enlouquecimento. Em outro viés, adotado por um número restrito de médicos, admitia-se que as moléstias mentais favoreciam a degeneração dos hábitos e o desapego aos princípios básicos de higiene, o que favorecia o doente a se tornar presa fácil da tuberculose. ${ }^{20}$

Um fato que chama a atenção é que a comprovação de tais hipóteses era buscada menos nas observações clínico-laboratoriais e muito mais nas composições literárias de ficção que, ao abandonarem a imagem romântica criada em torno dos pectários, instalaram em seu lugar as representações elaboradas pelos irmãos Goncourt cujos textos mostraram-se prolíficos em explorar personagens ensandecidos devido à doença pulmonar. No Brasil, apesar das ficções pioneiras assinadas por Machado de Assis, Cornélio Pena e Théo Filho sobre esse tema, a "psicologia do tuberculoso" ganhou maior destaque com o livro Floradas na serra, de autoria de Dinah Silveira de Queiroz, lançado em 1939. Imediatamente esta obra tornou-se fonte de discussões médicas, sendo avaliado por alguns tisiologistas como um texto que expunha com precisão as condições mentais dos pacientes tuberculosos. ${ }^{21}$

A confirmação científica da suposta existência de uma dimensão psicológica própria dos tísicos teve desdobramentos inclusive no Brasil. Em 1919 o alienista e primeiro diretor do Hospício de Juqueri, Francisco Franco da Rocha (1864-1933), publicou um texto comprometido com a explicação dos ensinamentos de Freud que, segundo o médico brasileiro, havia concluído que as nevroses (termo usado para designar a maior parte das doenças mentais) mostravam-se como consequências de "graves perturbações do sistema nervoso por intoxicações endógenas". ${ }^{22}$ Esta concepção foi assimilada por Pacheco e Silva, que havia sucedido Franco da Rocha tanto na direção do hospital para alienados mentais

19 PACHECO, op. cit., p. 368.

20 POROT, Maurice. Psicología del tuberculoso. Buenos Aires: Editorial Nova, 1946.

21 ALMEIDA PRADO, José Nascimento de. "Floradas na serra" e a psicopatologia. Gazeta Clínica, v. 37, n. 12, p. 457-460, dez. 1939; PARANHOS, Ulysses. Floradas na serra. Folha da Manhã, São Paulo, p. 6, 10 out. 1939.

22 FRANCO DA ROCHA, Francisco. A doutrina de Freud: resumo geral indispensável para a compreensão da psicoanálise. $2^{\mathrm{a}}$ ed., São Paulo: Nacional, 1930. p. 55-56. 
quanto na cátedra de Psiquiatria da Faculdade de Medicina da USP. A participação como perito na elaboração do laudo do assassino Amaral provavelmente pesou para que, em 1930, assim se pronunciasse nas páginas do manual que elaborou para a orientação dos médicos, estudantes e, sobretudo, para os enfermeiros que prestavam serviços em hospícios:

Qualquer infecção ou intoxicação tende sempre a atingir o ponto de menor resistência do organismo e, se este é o sistema nervoso, surgem as perturbações psíquicas. (...) Há, com frequência, uma relação evidente entre a tuberculose e certas formas de alienação mental, conquanto se não possa bem precisar o mecanismo pelo qual o bacilo da tuberculose atua sobre o cérebro, supondo-se que seja por meio de suas toxinas. Fato é, observado em quase todos os hospitais psicopáticos do mundo, que a tuberculose e a alienação mental andam sempre irmanadas. ${ }^{23}$

Diretor hospitalar prático e sempre atualizado em relação às discussões internacionais na área que se especializara, Pacheco e Silva buscou soluções para a acomodação dos loucos-tuberculosos. Em 1923, logo após assumir a direção do hospício, ele instituiu um pavilhão exclusivo para o acolhimento desses pacientes, fazendo construir um setor de isolamento dentro do nosocômio que, por si só, já se constituía em um território de segregação dos internados em relação à sociedade mais ampla.

O ambiente onde ocorria a dupla exclusão imposta aos indivíduos vitimados concomitantemente pela doença mental e pela moléstia pulmonar foi descrito por Pacheco e Silva na primeira edição do seu livro Cuidados aos psychopatas, mas ganhou contornos mais minuciosos, inclusive com registros fotográficos, na segunda edição da mesma obra, editada para atingir um público mais amplo que o composto por profissionais de saúde. A citação a seguir é extensa, mas também importante para o conhecimento das acomodações destinadas as loucos-tísicos:

Em todos os asilos do mundo a percentagem de alienados tuberculosos é relativamente elevada, tornando-se imprescindível o isolamento dos mesmos, sobretudo tendo-se em conta a impossibilidade de se conseguirem medidas de higiene entre doentes mentais.

Os grandes hospitais para alienados devem ser dotados de um pavilhão isolado destinado aos internados tuberculosos.

O Hospital do Juqueri dispõe de um moderno pavilhão com a capacidade para 96 doentes, dividido em duas seções, com o objetivo de isolar os pacientes conforme o estado mental e o grau da moléstia intercorrente.

Assim, há uma seção para os tuberculosos cuja moléstia tenha atingido um grau avançado; outra é destinada aos casos incipientes. Cada uma dessas seções comporta dois dormitórios, com capacidade para 24 doentes cada um. Os alienados raciocinantes ocuparão os dormitórios dos extremos e os que já tenham caído em estado demencial ficarão nos dormitórios centrais.

O edifício, que é térreo, tem um corpo central e duas alas laterais que avançam para a frente.

Cada seção ocupa uma ala e metade da parte central. Na parte central se encontram a sala do médico, depósitos, rouparia e uma sala destinada à 
helioterapia artificial.

(...)

O pavilhão tem o maior número possível de janelas, com vidraças do tipo "guilhotina", para permitir a entrada de ar puro, sem sujeitar os doentes a uma corrente direta de ar. As vidraças são de vidros Catedral ou Florentino, de uma mesma cor, os quais, sendo menos brilhantes que os vidros comuns, não prejudicam a visão.

A cobertura é feita de telhas francesas e o edifício não tem forro para facilitar a ventilação.

O dormitório ao ar livre está resguardado do vento sul e tem cobertura. O piso desse dormitório tem o mesmo nível dos demais, o que facilita o transporte de camas.

Os refeitórios têm uma copa dando acesso para o exterior, por onde são recebidas as refeições.

A rouparia dispõe de um aparelho de esterilização e saída para o exterior.

O pátio, que é delimitado pelo edifício e por uma cerca viva, ligando os extremos das alas, tem uma divisão central, cabendo um lado a cada seção.

No pátio, há distribuídos terraços cobertos, para repouso dos doentes, que aí recebem também as suas visitas. ${ }^{24}$

Mas, apesar de todos esses aparatos panópticos, o Hospício de Juqueri não dispunha dos serviços de um tisiologista para assistir os pacientes tuberculosos. O mesmo ocorria com o Manicômio Judiciário de Franco da Rocha - que décadas mais tarde iria ser rebatizado como Hospital de Custódia e Tratamento Psiquiátrico -, instalado em 1934 na grande fazenda onde se localizava o hospício, tinha como objetivo segregar e oferecer tratamento para os infratores portadores de graves distúrbios mentais. Isto impunha que o insano cuja vida estava sob risco imediato devido à tuberculose fosse transferido por algum tempo, ou até o advento do óbito, para um sanatório destinado ao atendimento dos tísicos pobres. Transitando entre o hospício e o hospital para tuberculosos, o louco-tísico era lançado em território ainda mais nebuloso, tornando-se presença indesejada e perigosa em ambas as instituições. Isto porque, no hospício, ele era temido, uma vez que se configurava em um agente disseminador do bacilo de Koch e, no sanatório, havia sempre o receio de que ele perturbasse a rotina regida pelos comportamentos comedidos e, além disso, suspeitava-se que ele poderia cometer assassinatos, estupros e outros crimes menos graves.

Vários pacientes afrodescendentes e entisicados do hospício e do manicômio judiciário localizados no atual município de Franco da Rocha foram encaminhados para o Hospital-sanatório São Luiz Gonzaga. Estabelecido em 1932 nas instalações do antigo Leprosário do Guapira, esse sanatório era mantido pela Irmandade de Misericórdia da Santa Casa paulistana, tendo como clientela a população de tuberculosos desprovidos de recursos. Uma pesquisa que explorou as informações preservadas nos arquivos do sanatório São Luiz Gonzaga revela as dificuldades de integração e de assistência aos pacientes classificados como "psicopatas

24 Idem. Cuidados aos psychopathas. $2^{\mathrm{a}}$ ed., Rio de Janeiro: Guanabara, 1934. p. 117-119. 
tuberculosos", não sendo raras as situações onde a instituição de origem se negava a receber de volta o paciente, forçando o sanatório a permanecer com o hóspede indesejado.

Mesmo assim, o sanatório do Jaçanã acabou encontrando uma função para esses pacientes. Desempenhando a tarefa de hospital-escola tanto da Faculdade de Medicina da USP quanto do Escola Paulista de Medicina, tornaram-se frequentes as situações em que esses internos eram usados para a instrução dos alunos das instituições médicas, momentos nos quais enfatizava-se as discussões sobre a "psicologia do tuberculoso". As anotações registradas nos prontuários mostram que, com frequência, o prof. Antônio de Almeida Prado, catedrático de Clínica Médica da escola uspiana, ministrava suas aulas no ambiente sanatorial, selecionando para discussão os casos de enfermos tísicos e doentes mentais, especialmente os sádicos, estupradores, homicidas, suicidas e "tarados" de todo tipo. Utilizando este critério, Almeida Prado descartava os prontuários que informavam sobre pacientes com traços do que então eram denominados "comportamentos mentais deturpados brandos", como os depressivos, abstinentes, chorões e ainda os pacientes que, mesmo tendo alta clínica, negavam-se a abandonar o isolamento sanatorial. ${ }^{25}$

\section{Considerações finais}

A TRAMA ALIMENTADA pela vida e pela morte do cidadão José Augusto do Amaral, assim como de tantos outros afrodescendentes pobres, enfermos e criminosos, encontrou explicações nos postulados médicos vigentes até pelo menos meados do século XX. Sob a rubrica da degeneração, determinaram os possíveis encaminhamentos impostos a esses pacientes. Aprisionado e destituído de assistência médica, de parentes e de amigos, Amaral sobreviveu poucos meses na cadeia. Outros infratores como ele foram condenados a viver suas existências em trânsito entre o hospício e o sanatório, estabelecimentos constantemente acusados pela própria imprensa do período como comprometidos mais em isolar seus internos tocados pela miséria do território dos sadios do que efetivamente tratar de suas moléstias mentais e físicas e também oferecer recursos para, quando eles fossem colados sem liberdade, pudessem se reintegrar na sociedade mais abrangente.

O "caso Amaral" não se constitui apenas em uma série de acontecimentos que marcaram a trajetória existencial de um indivíduo que, por seus atos e por seus traços físicos e psicológicos foi excluído primeiramente do mundo do trabalho e, na sequência, do convívio social mais amplo. Sua trajetória tem sido reprisada historicamente no contexto brasileiro, pois esses "trabalhadores invisíveis" têm sido alocados em uma trama política que dolorosamente os desqualifica como sujeitos sociais e frequentemente nega a eles a dignidade humana. Portanto, por mais que, eventualmente eles possam ser acusados de protagonistas de ações

25 BERTOLLI FILHO, Claudio. História social da tuberculose e do tuberculoso, 1900-1950. Rio de Janeiro: Ed. Fiocruz, 2001. p. 156. 
criminosas ou antissociais, na verdade eles são as principais vítimas da violência noticiada no cotidiano e insuflada por vozes que bradam "bandido tem que morrer", da mesma maneira que não são raros os eventos de assassinatos desses personagens condenados a viverem às margens do mundo do trabalho.

Como no passado, ainda hoje existe uma legião de homens e mulheres pobres que, levados à prisão devido a acusação de praticarem crimes horrendos, tornam-se rapidamente alvos de perícias médicas e do interesse da mídia, para em pouco tempo caírem no esquecimento e, se não encontrarem rapidamente a morte, viverem o resto de suas vidas em condições tão precárias quanto aquelas que padeciam quando em liberdade. A história dos brasileiros miseráveis, invocados recentemente por um conhecido repórter policial como "párias sociais", não pode ser lançada ao esquecimento.

Recebido em: 03/06/2020

Aprovado em:18/08/2020 